INTESTINE

\title{
Mislocalisation of hephaestin, a multicopper ferroxidase involved in basolateral intestinal iron transport, in the sex linked anaemia mouse
}

\author{
Y M Kuo, T Su, H Chen, Z Attieh, B A Syed, A T McKie, G J Anderson, J Gitschier, C D Vulpe
}

See end of article for

Gut 2004;53:201-206

authors' affiliations

Correspondence to: Assistant Professor C D Vulpe, Department of Nutrition and Toxicology, University of California, Berkeley, 119 Morgan Hall, Berkeley, CA 94720, USA; vulpe@uclink4. berkeley.edu

Accepted for publication 2 September 2003
Background: Hephaestin is a multicopper ferroxidase required for basolateral transport of iron from enterocytes. Sex linked anaemia (s/a) mice have a defect in the release of iron from intestinal enterocytes into the circulation due to an interstitial deletion in the hephaestin gene (heph).

Results: We have demonstrated that hephaestin is primarily localised to a supranuclear compartment in both intestinal enterocytes and in cultured cells. In normal intestinal enterocytes, hephaestin was also present on the basolateral surface. In sla mice, hephaestin was present only in the supranuclear compartment. In contrast, the iron permease Iregl localised to the basolateral membrane in both control and sla mice.

Conclusion: We suggest that mislocalisation of hephaestin likely contributes to the functional defect in sla intestinal epithelium.
I testinal absorption of iron is a critical step for regulating whole body iron levels because mammals possess a limited capacity to excrete excess iron. ${ }^{1}$ Although iron is crucial for the function of many proteins, the ability of iron to catalyse the formation of reactive oxygen species can contribute to pathological damage. ${ }^{2}$ Inherited disturbances of both cellular and whole body iron homeostasis illustrate the critical need to maintain a balance between deficiency and excess of this metal. ${ }^{3}$ Within mammalian cells, elaborate regulatory mechanisms exist to regulate iron entry, intracellular sequestration, and mobilisation. ${ }^{4-6}$ Recent identification of key components of intestinal iron transport has revealed new insights into molecular mechanisms regulating whole body iron homeostasis. ${ }^{6}$

One such component is hephaestin (Hp), a membrane bound homologue of ceruloplasmin $(\mathrm{Cp})$ that is required for iron egress from the enterocyte. Previously, we discovered this novel protein as defective in mice with sex linked anaemia (sla). ${ }^{7}$ Apical uptake of iron in enterocytes of sla mice is normal but basolateral export is decreased, leading to iron accumulation in enterocytes. ${ }^{89}$ sla mice contain an inframe deletion of 582 bases in the Heph gene resulting in a truncated protein. ${ }^{10} \mathrm{Hp}$ has an oxidase activity like $\mathrm{Cp}^{11}$ which may facilitate iron export from the intestine to plasma ${ }^{72}$ where it is found bound as $\mathrm{Fe}(\mathrm{III})$ to transferrin. Hp may work in concert with a basolaterally located Fe (II) permease, Iregl (also known as ferroportin or MTP1), ${ }^{13-15}$ in the export of iron from the enterocytes. ${ }^{16}$ For example, oxidation to Fe (III) by Hp may directly assist in the release of iron from Iregl or indirectly by maintaining an $\mathrm{Fe}(\mathrm{II})$ gradient. The activities of both $\mathrm{Cp}^{17-19}$ and the $S$ cerevisiae multicopper ferroxidase Fet $3 \mathrm{p}^{2021}$ are crucial for iron transport. Interestingly, a functional Fet $3 p$ is required for proper plasma membrane localisation of the yeast high affinity iron importer Ftrlp. ${ }^{22}$

Abbreviations: $\mathrm{Hp}$, hephaestin; $\mathrm{Cp}$, ceruloplasmin; sla, sex linked anaemia; Tfr, transferrin receptor; DAB, 3,3'-diaminobenzidine
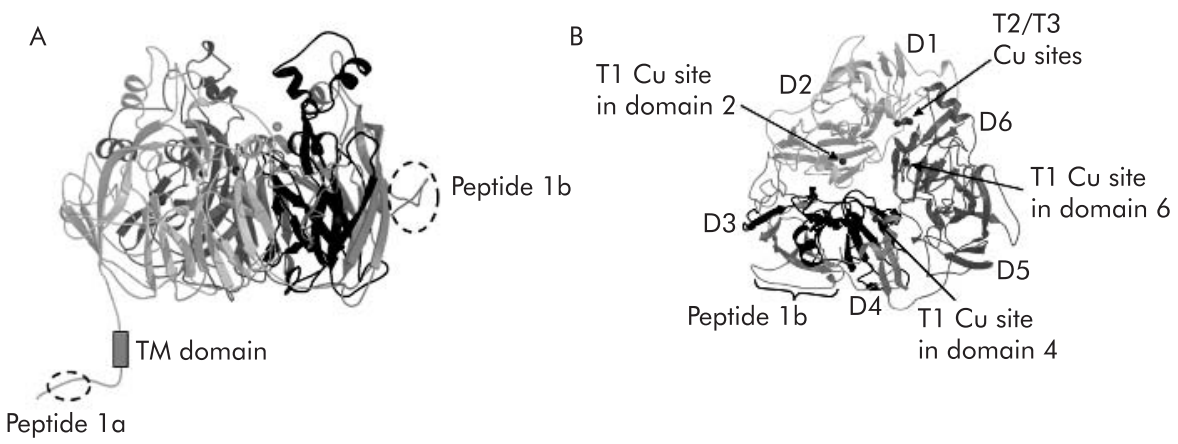

Figure 1 Location of peptide epitopes on hephaestin ( $\mathrm{Hp}$ ) and deleted region in sex linked anaemia (sla) mice. A ribbon diagram of a molecular model of mouse $\mathrm{Hp}$ is presented. (A) Side view of the mouse $\mathrm{Hp}$ molecule almost perpendicular to the pseudo-3-fold axis. Location of the two peptide epitopes ( $\mathrm{Hp}$ peptide la and $\mathrm{Hp}$ peptide $\mathrm{lb}$ ) are indicated. The region deleted in sla is shown in black. (B) Top view along the pseudo-3-fold axis showing the predicted domain structure of $\mathrm{Hp}$ with copper binding sites indicated, the $\mathrm{Hplb}$ peptide epitope, and the region deleted in sla in dark black. The figures were generated using a modified version of Molscript ${ }^{24}$ and subsequently rendered in Raster3D version 2.0..$^{25} 26$ 


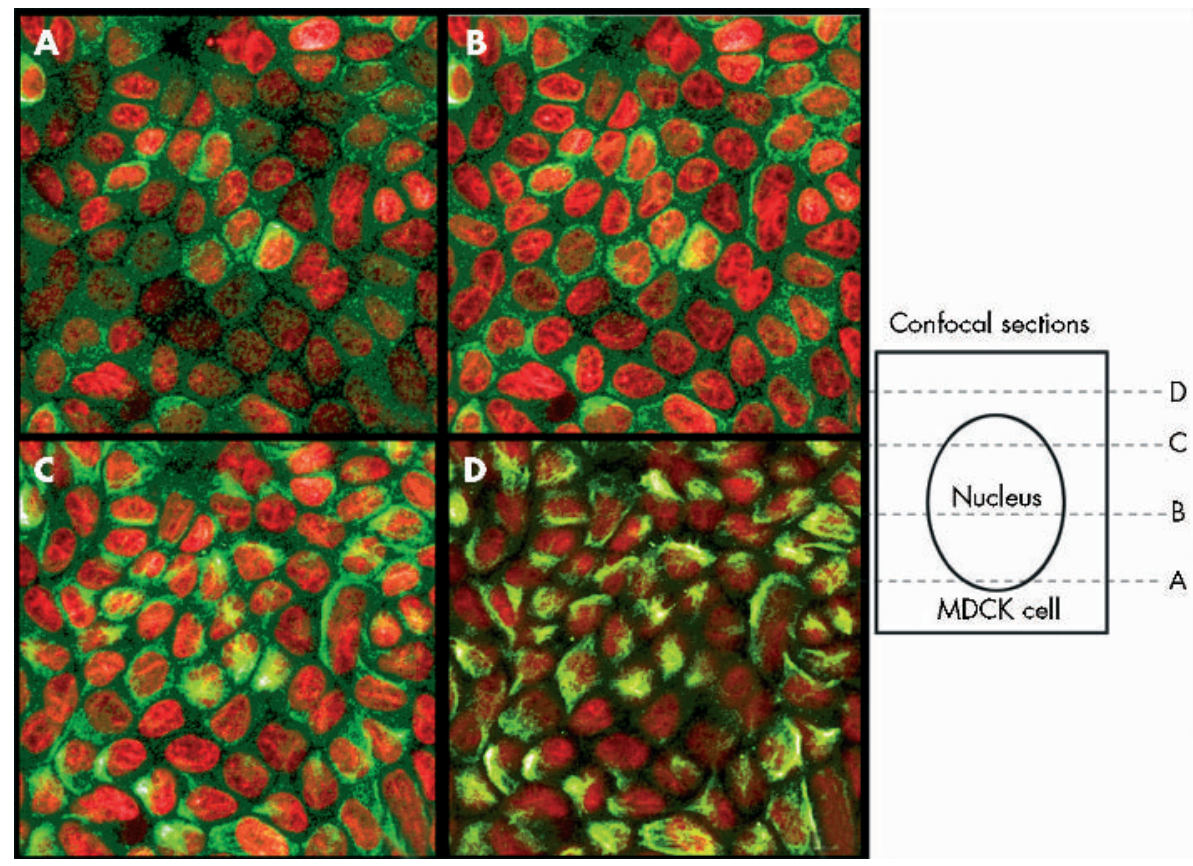

Figure 2 Apical supranuclear location of hephaestin (Hp) in MDCK cells. Confocal immunofluorescence microscopy was carried out using an affinity purified antiserum to the $\mathrm{C}$ terminus of $\mathrm{Hp}$ in cultured MDCK cells. Hp staining is represented in green and nuclei are in red. Sequential confocal reconstructions from the bottom (A) to the top (D) of the cell showed predominantly apical perinuclear staining of $\mathrm{Hp}$.

Here we show that $\mathrm{Hp}$ is located primarily in apical supranuclear and basolateral membranes in mature intestinal enterocytes. The truncated version of $\mathrm{Hp}$ in the sla mouse is detectable only in a supranuclear intracellular compartment. Targeting of Iregl is not affected in the sla mouse and
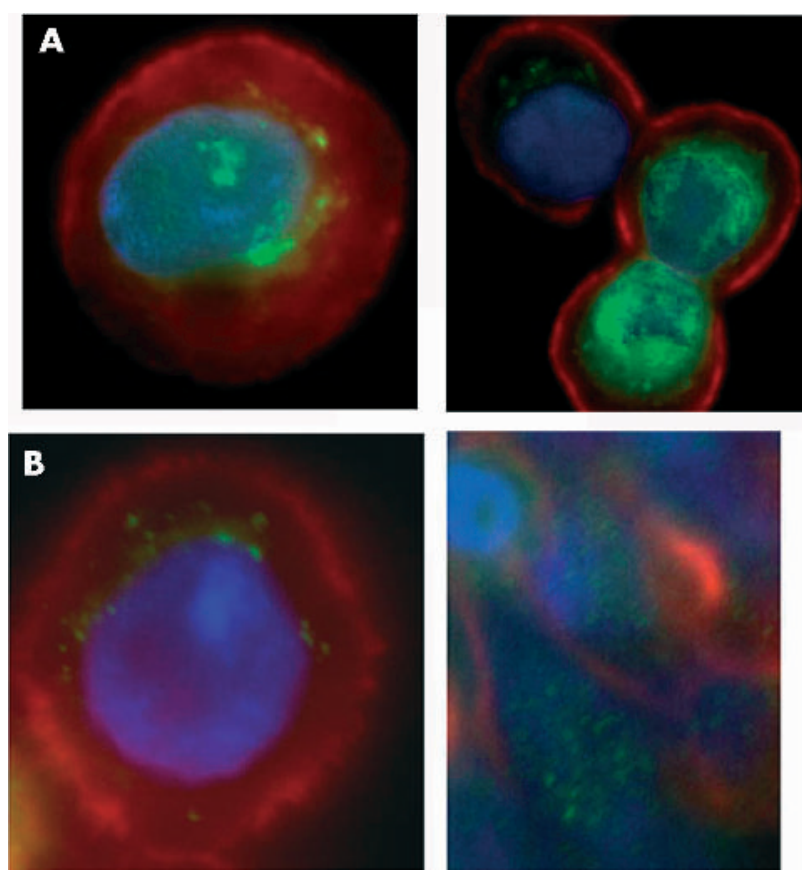

Figure 3 Apical supranuclear location of hephaestin (Hp) in HT29 cells. (A) Immunofluorescence microscopy using an affinity purified antiserum to the $\mathrm{C}$ terminus of $\mathrm{Hp}(\mathrm{HplA})$ in cultured HT29 cells. (B) Immunofluorescence microscopy using an affinity purified antiserum to the more $\mathrm{N}$ terminal part of $\mathrm{Hp}(\mathrm{Hp} 2 \mathrm{a})$ in cultured $\mathrm{HT} 29$ cells. A single cell is shown in panels to the left and several cells are shown in the right hand panels. Hp staining is shown in green, actin in red, and nuclei in blue. the predicted basolateral location was seen. We suggest that improper localisation of $\mathrm{Hp}$ contributes to the defect in basolateral iron transport in sla mice.

\section{METHODS}

\section{Antisera to hephaestin and Ireg 1}

We used two affinity purified anti-Hp peptide antisera which we previously demonstrated to be specific for $\mathrm{Hp}$ from multiple species with no cross hybridisation to $\mathrm{Cp} .{ }^{10}$ $\mathrm{Hp}$, in contrast with $\mathrm{Cp}$, has a $\mathrm{C}$ terminal transmembrane domain and presumed cytosolic domain (fig l). One antiserum, Hpla, was raised against a peptide corresponding to the $C$ terminal 15 amino acids (QHRQRKLRRNRRSIL), predicted to be on the cytoplasmic surface of the membrane. The second antiserum, Hplb, was raised against a peptide corresponding to amino acids 435-52 (AFQDETFQERVHQEEETH) of mouse Hp (Genbank accession: AAD 16035). This sequence resides within Hp domain $2,{ }^{23}$ predicted by homology modelling to be located on a solvent accessible portion of the Hp protein. ${ }^{23}$ The sla mouse contains deletion of 192 amino acids (shown in black in fig 1) which does not include the regions to which the antisera were raised. Affinity purified rabbit anti-Iregl (CGKQLTSPKDTEPKPLEGTH) antiserum was made using the same protocol as above. We have previously demonstrated the specificity of this antiserum for Iregl. ${ }^{10}$

\section{Cell immunostaining}

MDCK cells were grown on Transwell filters (Costar-Corning Life Sciences, Acton, Massachusetts, USA) and Cos7 and HT29 cells were grown on LabTekII chamber slides (Nalge Nunc International, Rochester, New York, USA) in Dulbecco's modified Eagle's medium. Non-differentiated HT29 cells were grown in McCoy's medium until 70\% confluency. Cell media was supplemented with $10 \%$ fetal bovine serum and $1 \%$ penicillin-streptomycin cocktail. Cells were fixed for 20 minutes in $4 \%$ paraformaldehyde. Cells were made permeable with $0.25 \%$ saponin (Sigma, St Louis, Missouri, USA), $0.7 \%$ bovine serum albumin (Sigma), and 0.7\% normal 

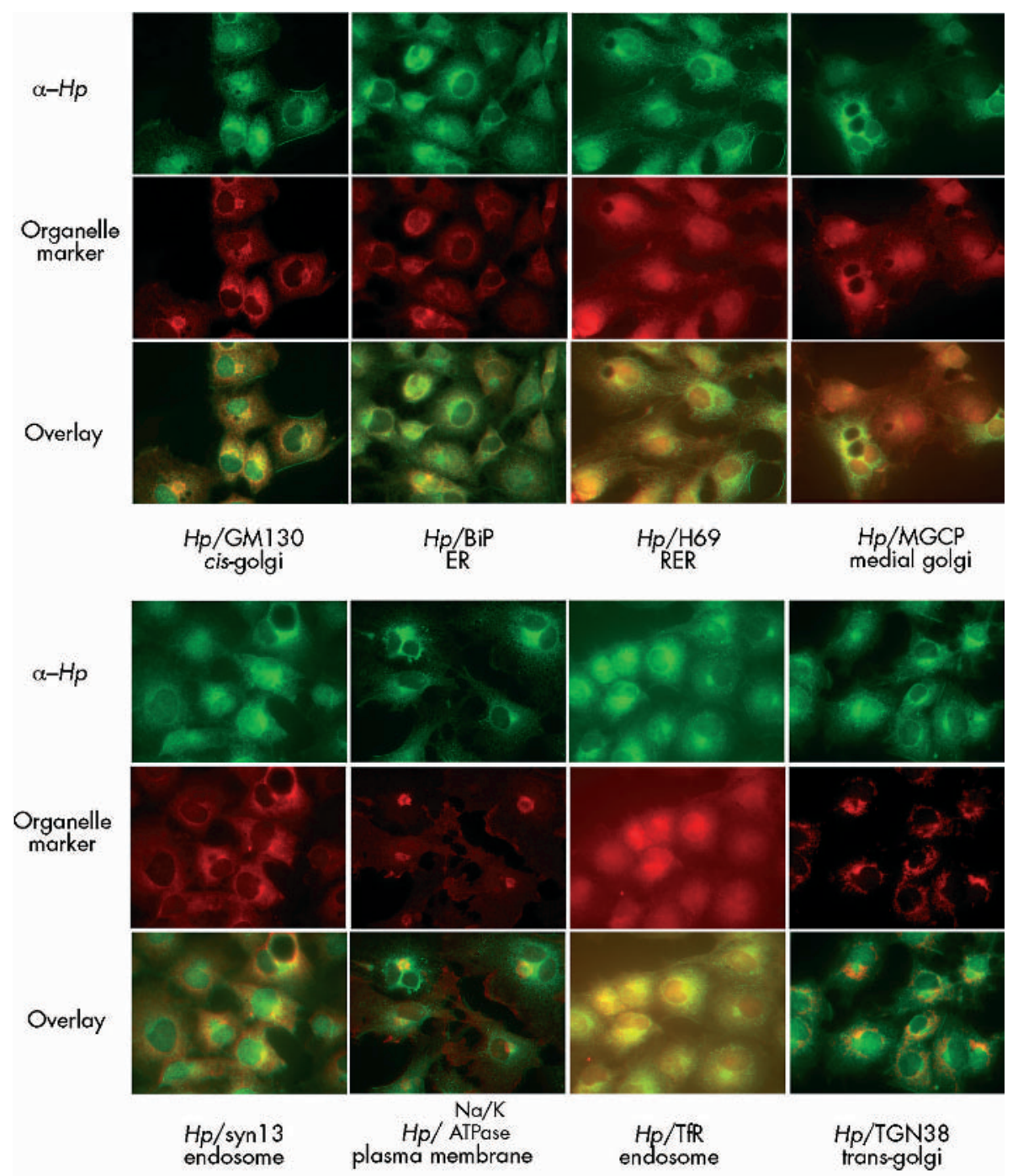

Figure 4 Colocalisation of hephaestin $(\mathrm{Hp})$ with subcellular markers. Colocalisation of affinity purified antibodies to the $\mathrm{C}$ terminus of $\mathrm{Hp}(\mathrm{Hp} \mathrm{A})$ and antibodies to various subcellular markers in cultured CoS7 cells. Hp staining is represented in green and the markers (TfR, TGN38, GM130, BiP, H69, $\mathrm{Na}$, K-ATPase, MGCP, and syntaxin 13) are shown in red. Yellow in the overlays indicates colocalisation. ER, endoplasmic reticulum; RER, rough endoplasmic reticulum; Tfr, transferrin receptor.

goat serum (Cappel-MP Biomedicals Inc., Irvine, California, USA). Primary and secondary antibodies were diluted in $1 \%$ normal goat serum, $0.7 \%$ bovine serum albumin, and $0.1 \%$ saponin. The rabbit antimouse Hp antibody la (1:200) was visualised using a goat AlexaFluor488 antirabbit IgG antibody (molecular probes and nuclei visualised with propidium iodide; Molecular Probes, Eugene, Oregon, USA) or 4'-6diamidino-2-phenylindole (Molecular Probes) staining. Coimmunolocalisation studies involved the following antisera: rat antimouse-CD71 (transferrin receptor (Tfr)) for endosomes (Serotec, Raleigh, North Carolina, USA); mouse antiTGN38 for trans- Golgi network (Transduction Laboratories, BD Biosciences, San Jose, California, USA); mouse antiGM130 for cis-Golgi (Transduction Laboratories); mouse anti-BiP/GRP78 for endoplasmic reticulum (Transduction Laboratories); rat anti-H69 for rough endoplasmic reticulum (Developmental Studies Hybridoma Bank, Iowa City, Iowa, USA); mouse anti- $\mathrm{Na}^{+}, \mathrm{K}^{+}$-ATPase for plasma membrane (Developmental Studies Hybridoma Bank); rat anti-ABL70 for medial Golgi cisternae (Developmental Studies Hybridoma Bank); and mouse antisyntaxin 13 for endosomes (Stressgen, San Diego, California, USA). Alexa 594 labelled antirat or antimouse IgG (Molecular Probes) were used as secondary antisera. F-actin of HT29 cells was stained with 1:4000 rhodamine phalloidin (Molecular Probes, R-415) for one hour at room temperature. Cells were examined at $100 \times$ magnification on a Nikon E800 microscope and images captured using a Spot II digital camera. Confocal images were visualised and captured as a $\mathrm{Z}$ series using a Bio-Rad confocal microscope.

\section{Immunostaining for $\mathrm{Hp}$ and Ireg $\mathrm{l}$ in mouse duodenal sections}

The sla mice were originally obtained from Jackson Laboratories (Bar Harbor, Maine, USA) and maintained on a C57BL/6J background at the Queensland Institute of Medical Research and University of California, Berkeley (California, USA) for nine years prior to this study. Mouse duodenum from C57BL/6J or sla mice were isolated and fixed for 12-14 hours in Bouins fixative (Sigma), organs were washed in $70 \%$ ethanol, dehydrated, embedded in paraffin, and sectioned $(8 \mu \mathrm{M})$ as previously described.$^{27}$ Sections were immunostained using standard procedures with the affinity purified antiserum to the C terminus of Hp (la) or Ireglat 

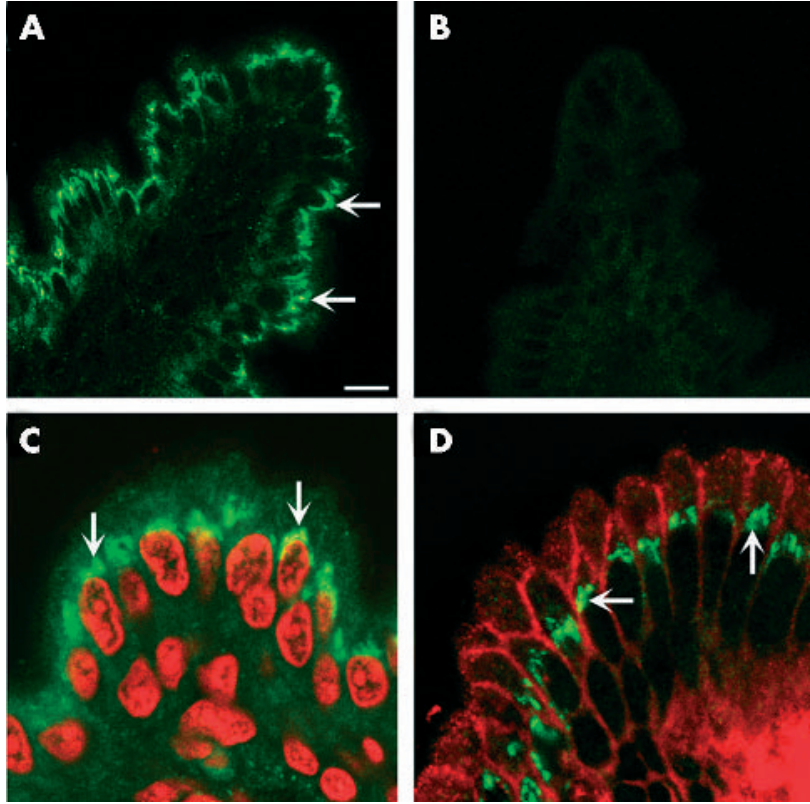

Figure 5 Predominant supranuclear location of hephaestin $(\mathrm{Hp})$ in duodenal enterocytes. Immunofluorescent staining of duodenal sections from C57BL/6J mice on control diets using an antiserum to the $C$ terminus of $\mathrm{Hp}$ demonstrated predominantly supranuclear staining. (A) $\mathrm{Hp}$ alone (green). (B) Preincubation with $\mathrm{Hp}$ peptide. (C) Propidium iodide staining of nucleus (in red) and $\mathrm{Hp}$ staining (in green). (D) Immunolocalisation of $\mathrm{Hp}$ (green) and $\mathrm{Na}^{+}, \mathrm{K}^{+}$-ATPase (red).

1:200 dilution and enhanced with ABC Elite Vector Stain Substrate Kit (Vector Laboratories, Burlingame, California, USA) using the manufacture's protocol. Staining was visualised with 3,3'-diaminobenzidine (DAB substrate kit; Vector Laboratories) and counterstained with Gill's haematoxylin No 2 (Polysciences Inc., Warrington, Pennsylvania, USA) including the nickel solution for $\mathrm{Hp}$ staining. For peptide blocking studies, anti-Hpla 1:200 was preadsorbed
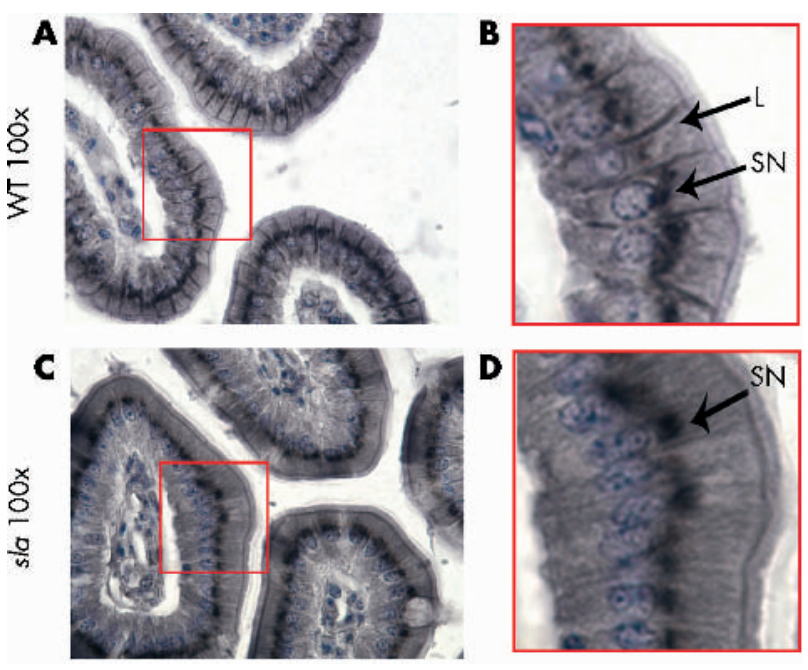

Figure 6 Absence of basolateral hephaestin $(\mathrm{Hp})$ on duodenal enterocytes from sex linked anaemia (s/a) mice. 3,3'-Diaminobenzidine immunohistochemistry of duodenal sections using an antiserum to the $C$ terminus of $\mathrm{Hp}$. (A) $100 \times$ of C57BL/6J (WT) duodenal sections; (B) $3 \times$ magnification of boxed area in (A). Arrows indicate lateral (L) and supranuclear (SN) staining. (C) 100x of sla duodenal sections; (D) $3 \times$ magnification of boxed area in (C). Arrows indicate supranuclear (SN) staining. There was no appreciable lateral staining.
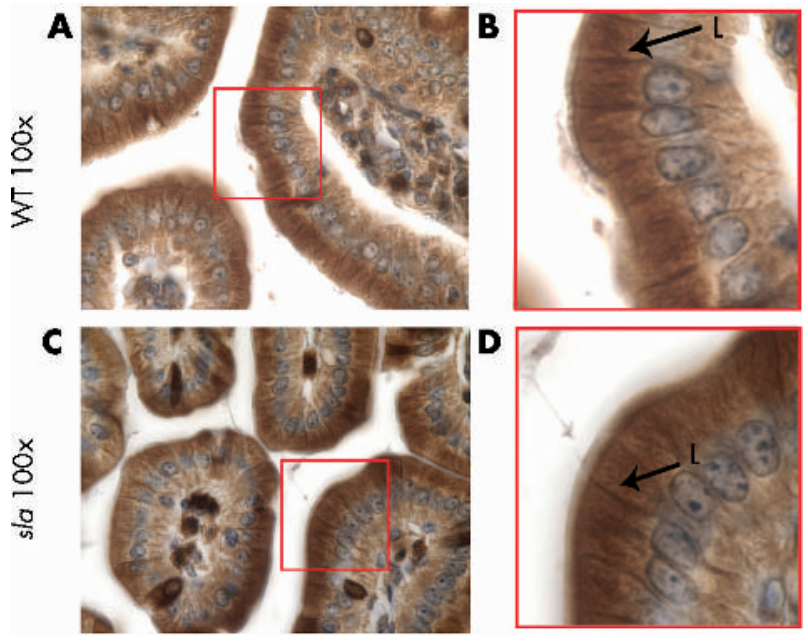

Figure 7 Basolateral Ireg1 in duodenal enterocytes from sla mice. 3,3' Diaminobenzidine immunohistochemistry of duodenal sections using an antiserum to Iregl. (A) $100 \times$ of C57BL/6J (WT) duodenal sections:

(B) $3 \times$ magnification of boxed area in (A). Arrows indicate lateral (L) staining. (C) $100 \times$ of sla duodenal sections; (D) $3 \times$ magnification of boxed area in (C).

with $10^{-5} \mathrm{M}$ peptide (the same peptide to which the antiserum was raised) for 48 hours at $4^{\circ} \mathrm{C}$ and then used as above. Co-immunolocalisation with mouse anti- $\mathrm{Na}^{+}, \mathrm{K}^{+}$ATPase was as described above for cell culture. Sections were examined using a Nikon E800 microscope and images captured using a Spot II digital camera.

\section{RESULTS}

\section{Predominantly supranuclear localisation of}

\section{hephaestin in cultured cells}

Immunofluorescence studies with affinity purified polyclonal antisera to $\mathrm{Hp}$ in the cultured canine kidney (MDCK) and intestinal (HT29) cell lines showed a predominantly supranuclear distribution under standard culture conditions (figs 2 and 3). Confocal sections of the MDCK cells (fig 2) showed clear supranuclear staining (in green) with the antiserum to the $\mathrm{C}$ terminus of Hp. Similarly, supranuclear staining was seen in HT29 cells grown in standard culture conditions with antisera to both the $\mathrm{C}$ terminal and $\mathrm{N}$ terminal regions of $\mathrm{Hp}$. We therefore concluded that $\mathrm{Hp}$ is primarily localised in a supranuclear location in cultured cells.

\section{Colocalisation studies suggest recycling endosome and/or cis-Golgi location of $\mathrm{Hp}$}

To identify the subcellular compartment containing $\mathrm{Hp}$, we carried out colocalisation studies with a series of antisera to organelle specific marker proteins, as detailed in the methods section above. Cos7 cells were used because they express abundant $\mathrm{Hp}$ and have a large cytoplasm/nucleus ratio. These studies suggest that $\mathrm{Hp}$ colocalises with the recycling endosome compartment identified by Tfr (fig 4). There was also considerable colocalisation with the cisGolgi compartment identified by the GM130 marker (fig 4).

\section{Supranuclear and basolateral location of hephaestin in enterocytes}

We investigated the cellular localisation of $\mathrm{Hp}$ in $\mathrm{C} 57 \mathrm{BL} / 6 \mathrm{~J}$ mice. Immunofluorescence studies showed an apical supranuclear signal in duodenal enterocytes (fig 5A, C) which was blocked by the immunising peptide or was absent in sera adsorbed with the immunising peptide (fig 5B). Given the 
role of $\mathrm{Hp}$ in the basolateral export of iron, we conducted colocalisation studies using antibodies to both $\mathrm{Hp}$ and the basolateral marker $\mathrm{Na}^{+}, \mathrm{K}^{+}$-ATPase. Surprisingly, these studies showed little overlap between the two proteins (fig 5D). We conclude that the majority of Hp protein is located in an apical supranuclear compartment in C57BL/6J mice.

Although immunofluorescence studies using fresh frozen and PFA fixed tissues provide an excellent means of detecting the predominant location of a protein, secondary less abundant populations of protein may be overlooked. We therefore used paraffin embedded intestinal sections and staining with avidin-biotin complex horseradish peroxidase followed by DAB staining. As seen in fig 6A and B, this approach revealed that $\mathrm{Hp}$ was present on the lateral surfaces of the enterocytes in C57BL/6 $\mathrm{J}$ mice as well as abundant in an apical supranuclear location.

\section{Hephaestin in sla mice is primarily intracellular}

In marked contrast, Hp expression in sla mice was confined to the supranuclear location with no appreciable basolateral staining (fig 6C, D). The absence of $\mathrm{Hp}$ in the basolateral membrane may contribute to the decreased transfer of iron into the circulation and contribute to the iron deficiency in sla mice.

Ireg 1 in sla mice located on the basolateral membrane To address whether inappropriate localisation of $\mathrm{Hp}$ in sla leads to changes in Iregl targeting, we immunolocalised Ireg 1 in intestinal enterocytes of $\mathrm{C} 57 \mathrm{Bl} / \mathrm{J}$ type and sla mice (fig 7). We found Iregl on the basolateral surfaces of enterocytes in both control and mutant mice. We conclude that inappropriate localisation of $\mathrm{Hp}$ does not affect the location of the Iregl protein.

\section{DISCUSSION}

We have proposed that $\mathrm{Hp}$ ferroxidase activity may be necessary for effective release of iron following transport through the basolateral membrane by the iron transporter Ireg $1 .^{7}$ Our finding of $\mathrm{Hp}$ on or near the basolateral membrane of the intestinal enterocyte provides support for this hypothesis. However, the predominant apical supranuclear location in multiple cultured cell lines and mature enterocytes suggests intracellular trafficking of $\mathrm{Hp}$, an additional intracellular function, or both. The exact cellular compartment remains uncertain as immunolocalised $\mathrm{Hp}$ did not completely colocalise with any one organelle marker. Considerable overlap with the transferrin receptor (Tfr) suggests the recycling endosome but cisGolgi remains a possibility, or both locations. Hp is predicted to be a multicopper ferroxidase based on sequence similarity with $\mathrm{Cp}$ and conservation of structural features. ${ }^{23}$ Copper is assembled into $\mathrm{Cp}$ in the $\mathrm{Golgi}^{28}$ and it is reasonable to suggest copper is also incorporated into $\mathrm{Hp}$ at this point. Detection of $\mathrm{Hp}$ in Golgi may reflect this assembly process. Localisation in recycling endosomes is more difficult to explain and suggests that $\mathrm{Hp}$, like Tfr, may cycle between the basolateral membrane and the recycling endosome, with the bulk of the protein at any one time in the endosome. Alternatively, the supranuclear compartment may not represent the recycling endosome or cis-Golgi but a distinct compartment of unknown function. The functional role of $\mathrm{Hp}$, if any, in this location is not known, particularly as Iregl is not found in this location.

Despite an inframe interstitial deletion removing 192 amino acids, sla mice still produce a truncated Hp protein. ${ }^{10}$ In sla mice, Hp is located exclusively (within the limits of our detection) within a supranuclear compartment. Absence of Hp from the basolateral membrane in sla mice, and thus its unavailability for interaction with the basolaterally located Iregl, may contribute to the observed iron transport defects in sla. For example, Iregl may have diminished efflux capacity in the absence of Hp. The supranuclear localisation of $\mathrm{Hp}$ in sla could result from constitutive inappropriate localisation of the truncated Hp protein. The mutant protein may not fold appropriately leading to retention in the supranuclear region or the region deleted in sla could contain necessary basolateral targeting information. In contrast with the Fet $3 p / F t r l p$ complex in yeast where the proper localisation of Ftrlp (the Iregl functional orthologue) on the plasma membrane depends on a functional Fet3p (the hephaestinlike molecule), ${ }^{22}$ the basolateral location of Iregl in sla suggests that proper targeting of Iregl is not dependent on Hp.

\section{ACKNOWLEDGEMENTS}

This work was supported by grants NIH 5-R01-DK57800, NIH 5-R01DK56376, and K08 DK2823 to CV and by NIH R01- DK047192 to JG. JG. is an investigator with the Howard Hughes Medical Institute. The antibodies developed by Thomas August and James Hildreth were obtained from the Developmental Studies Hybridoma Bank developed under the auspices of the NICHD and maintained by the University of Iowa, Department of Biological Sciences, Iowa City, IA 52242, USA.

\section{Authors' affiliations}

Y M Kuo, J Gitschier, Departments of Medicine and Pediatrics and Howard Hughes Medical Institute, University of California, San Francisco, CA 94143-0794, USA

T Su, H Chen, Z Attieh, C D Vulpe, Department of Nutritional Sciences and Toxicology, University of California, Berkeley, CA 94720-3104, USA

B A Syed, Metalloprotein Research Group, The Randall Centre, New Hunts House, Kings College London, SEl 9RT, UK

A T McKie, Department of Molecular Medicine, King's College, London SE5 9NU, UK

G J Anderson, Queensland Institute of Medical Research and the University of Queensland, Post Office Royal Brisbane Hospital, Brisbane, Queensland 4029, Australia

\section{REFERENCES}

1 Bothwell TH, Charlton RW, Cook JD, et al. Iron metabolism in man. Oxford: Blackwell Scientific Publications, 1979:256-83.

2 Harris WR. Iron chemistry. In: Templeton DM, ed. Molecular and cellular iron transport. New York: Marcel Dekker Inc, 2002:1-40.

3 Andrews NC. Animal models of iron transport and storage disorders. In: Templeton DM, ed. Molecular and cellular iron transport. New York: Marcel Dekker Inc, 2002:679-97.

4 Johansson HE, Theil EC. Iron-response element (IRE) structure and combinatorial RNA regulation. In: Templeton DM, ed. Molecular and cellular iron transport. New York: Marcel Dekker Inc, 2002:237-53.

5 Hanson EH, Leibold EA. Regulation of iron homeostasis by iron regulatory proteins 1 and 2. In: Templeton DM, ed. Molecular and cellular iron transport. New York: Marcel Dekker Inc, 2002:207-35.

6 Templeton DM. Molecular and cellular iron transport. New York: Marcel Dekker Inc, 2002.

7 Vulpe C, Kuo Y-M, Libina N, et al. Hephaestin, a ceruloplasmin homologue implicated in intestinal iron transport, is defective in the sla mouse. Nat Genet 1999;21:195-9.

8 Edwards JA, Bannerman RM. Hereditary defect of intestinal iron transport in mice with sex-linked anemia. J Clin Invest 1970;49:1869-71.

9 Manis J. Intestinal iron-transport defect in the mouse with sex-linked anemia. Am J Physiol 1971;220:135-9.

10 Chen H, Su T, Attieh ZK, et al. Systemic regulation of hephaestin and Iregl revealed in studies of genetic and nutritional iron deficiency. Blood 2003;102:1893-9.

11 Attieh Z, Alaeddine RM, Su T, et al. Identification of a ferroxidase activity for hephaestin. Proccedings of Bioiron-World Congress on Iron Metabolism, Cairns, Australia. J Clin Gastroenterol 2001 (in press).

12 Frazer DM, Vulpe CD, McKie AT, et al. Cloning and gastrointestinal expression of rat hephaestin: relationship to other iron transport proteins. Am J Physiol Gastroint Liver Physiol 2001;281:G931-9.

13 Donovan A, Brownlie A, Zhou Y, et al. Positional cloning of zebrafish ferroportin 1 identifies a conserved vertebrate iron exporter. Nature 2000;403:776-81. 
14 Abboud S, Haile DJ. A novel mammalian iron-regulated protein involved in intracellular iron metabolism. J Biol Chem 2000;275:19906-12.

15 McKie AT, Marciani P, Rolfs A, et al. A novel duodenal iron-regulated transporter, IREG1, implicated in the basolateral transfer of iron to the circulation. Mol Cell 2000:5:299-309.

16 Anderson GJ, Vulpe CD. Regulation of intestinal iron transport. In: Templeton DM, ed. Molecular and cellular iron transport. New York: Marcel Dekker Incl, 2002:559-96

17 Disilvestro RA. Influence of dietary copper, copper injections and inflammation on rat serum ceruloplasmin activity levels. Nutr Res 1990;10:355-8.

18 Cerone SI, Sansinanea AS, Streitenberger SA, et al. Cytochrome c oxidase $\mathrm{Cu}, \mathrm{Zn}$-superoxide dismutase, and ceruloplasmin activities in copper-deficient bovines. Biol Trace Elem Res 2000;73:269-78.

19 Yamada T, Agui T, Suzuki Y, et al. Inhibition of the copper incorporation into ceruloplasmin leads to the deficiency in serum ceruloplasmin activity in LongEvans cinnamon mutant rat. J Biol Chem 1993;268:8965-71.

20 Askwith C, Eide D, Ho AV, et al. The FET3 gene of S. cerevisiae encoes a multicopper oxidase required for ferrous iron uptake. Cell 1994;76:403-10.
21 Desilva DM, Askwith CC, Eide D, et al. The Fet3 gene product required for high affinity iron transport in yeast is a cell surface ferroxidase. J Biol Chem 1995;270:1098-101.

22 Stearman R, Yuan DS, Yamaguchi-Iwai, et al. A permease-oxisdase complex involved in high-affinity iron uptake in yeast. Science 1996:271:1552-7.

23 Syed BA, Beaumont NJ, Patel A, et al. Analysis of the human hephaestin gene and protein: comparative modelling of the $\mathrm{N}$-terminus ecto-domain based upon ceruloplasmin. Protein Eng 2002;15:205-14

24 Esnouf RM. An extensively modified version of MolScript that includes greatly enhanced coloring capabilities. J Mol Graph Model 1997;15:132-4, 112-3

25 Bacon DJ, Anderson WF. A fast algorithm for rendering space-filling molecule pictures'. Seventh Annual Meeting of the Molecular Graphics Society. J Mol Graph 1988;6:219-20.

26 Merritt EA, Murphy MEP. Raster3D version 2.0-a program for photorealistic molecular graphics. Acta Cryst 1994;D50:869-73.

27 Kuo YM, Gitschier J, Packman S. Developmental expression of the mouse mottled and toxic milk genes suggests distinct functions for the Menkes and Wilson disease copper transporters. Hum Mol Genet 1997;6:1043-9.

28 Hellman NE, Gitlin JD. Ceruloplasmin metabolism and function. Annu Rev Nutr 2002;22:439-58.

\section{GI SNAPSHOT}

Answer

From question on page 161

Although anticoagulation for cerebral sinus thrombosis remains controversial, a recent Cochrane review concluded that anticoagulation was safe and associated with a potentially important reduction in the risk of death or dependency. In this case, following discussion with neurologists, she was anticoagulated for a four month period. Her vision slowly improved but did not return to normal. No prothrombotic state other than her inflammatory bowel disease (IBD) and her being on the pill could be identified. The pill was stopped and she was counselled on different methods of contraception.

In IBD, histological and haematological studies suggest that a hypercoaguable state is involved in the pathogenesis of venous thrombosis. The exact mechanism is unknown but is bound to be multifactorial. During acute flare up there are increases in factor VIII, fibrinogen, platelets, and factor $\mathrm{V}$, and a decrease in antithrombin III, all of which may contribute. Thrombosis in IBD is important because it occurs in young patients, often in unusual sites such as cerebral venous sinuses, and is associated with significant morbidity and mortality. The majority of patients in a flare up will be in a hypercoaguable state and therefore young patients should be treated aggressively with rehydration therapy, prophylactic heparin, as well as conventional treatment for their IBD to try and minimise the risk of thrombosis. 